tions on the anesthetic effect of the combination of xenon and halothane. Anesthesiology 1969; 31: 305-9.

4 Eger EI II, Larson CP Jr. Anaesthetic solubility in blood and tissues: values and significancc. Br J Anaesth 1964; 36: 140-9.

5 Luttropp HH, Rydgren $G$, Thomasson $R$, Werner O. A minimal-flow system for xenon anesthesia. Anesthesiology 1991; 75: 896-902.

\section{Epidural catheter connector}

To the Editor:

1 read with great interest the letter by Drs. Mclntyre and Kuwahara.' However, I cannot endorse the logic of using a butterfly needle because as the work was carried out in children, it may not be ideal. The value of the butterfly needle as an alternative paediatric epidural catheter connector in children has not been questioned, but there may be some dangers. One wonders how practical it is to have a sharp tip needle inside a catheter. Despite proper fixation, children are often restless and needlc-stick injury ${ }^{2}$ may be inevitable or there may be damage of the catheter which will invite infection and leakage. The increasing interest in continuous epidural blockade is remarkable. The availability and adaptability of various devices such as iv cannulas are considerable, which may substitute not only for paediatric epidural catheter connectors but also in adults. The hub of the iv cannula accepts any type of Luer-lock connection.

An appropriate size of an iv cannula fixed firmly inside the proximal end of the catheter and withdrawal of the needle will solve connector-catheter related problems.

Shamsul Alam MBBS

Department of Anesthesiology

Shimane Medical University

89-1, Enya-cho, Izumo 693

Japan

\section{REFERENCES}

1 McIntyre DR, Kuwahara B. Paediatric epidural catheter connector problems [Letter]. Can J Anaesth 1991; 38: 544.

2 Jagger J, Hunt EH, Brand-Elnaggar J, Pearson RD. Rates of needle-stick injury caused by various devices in a university hospital. N Engl J Med 1988; 319: 284-8.

\section{REPLY}

Dr. Alam raises a theoretical concern about needlestick injury when using a butterfly infusion set as a connector for epidural catheters in children. In reality, needlestick injury does not occur when suitable care and attention are directed to protecting the needle and the butterfly. We have used this type of connection for all of our epidural catheters at the Alberta Children's Hospital over the past 5 years, and not one of our patients has experienced a needlestick injury of the described type.

The needle is protected using a plastic sheath and the butterfly is wrapped in a gauze and plastic dressing, as we described in our initial communication.' We place a gauze dressing on the chest, the needle on top of the gauze and a plastic Tegaderm ${ }^{\circledR}$ dressing over the top of the needle.
We have had catheter disconnects with subsequent leakage of infusate but as mentioned in the original communication the incidence of this is far less than with the previous Tuohy crimp on style connector. Others have described alternative solutions with the use of tape ${ }^{2}$ or glue. ${ }^{3}$

Brian Kuwahara MD FRCPC

Kim Klassen ORT

Pain Service Co-ordinator

Department of Anesthesia

Alberta Children's Hospital

Calgary, Alberta

\section{REFERENCES}

I McIntyre D, Kuwahara B. Paediatric epidural catheter connector problems (Letter). Can J Anaesth 1991; 38: 544.

2 Gavelin RJ, Patterson KW. Epidural catheter disconnection (Letter). Can J Anacsth 1993; 40: 468.

3 Aldrete JA. Securing epidural catheters to Tuohy connectors (Letter). Anesthesiology 1995; 82: 320.

\section{Augustine guide}

To the Editor:

In their evaluation of the Augustine guide, Carr et al. ${ }^{1}$ graded laryngoscopic views according to Samsoon and Young's modification of Cormack and Lchane's scheme, ${ }^{2.3}$ stating "During direct laryngoscopy, the vocal cords and laryngeal inlet could not be seen (Cormack and Lehane grade IV)..." In fact, not seeing the vocal cords is grade III, grade IV being reserved for a hidden epiglottis:

Grade 2. If only the posterior extremity of the glottis is visible... Grade 3. If no part of the glottis can be seen, but only the epiglottis ... Grade 4 . If not even the epiglottis can be exposed... This situation is well recognized where there is obvious pathology, but is exceedingly rare if the anatomy is normal. ${ }^{2}$

Grade II, only posterior commissure visible; grade III, only tip of epiglottis visible; grade IV, no glottis [sic] structure visible. ${ }^{3}$

Additional confusion stems from downplaying the difference between the glottis (vocal cords and intervening opening) and the laryngeal inlet (oblique aditus including the upper border of the epiglottis, arycpiglottis folds containing the corniculate and cuneiform cartilages, and mucosa covering the arytenoidcus muscle). ${ }^{4}$

Though the incidence in apparently normal patients of grade IV approximates $<1 / 100,000,{ }^{2} 17 / 27$ of the current group had grade IV views, eight of them unanticipated. Even if Cormack and Lehane overstated by a factor of 10 the rarity of grade IV, a population of 80,00 would be necessary to turn up eight patients so difficult. If each of the four participants intubated the tracheas of 1,000 patients annually, trials would seem to have had to extend back to the mid-70s! The Augustine Guide was introduced in 1993.

Parenthetically, was intubation attempted with straight blades, and was optimal laryngeal pressure combined with laryngoscopy before resorting to the Augustine Guide?

Ronald M. Meyer MD

Department of Anesthesia 